\title{
CORRESPONDENCE.
}

MR. FINLAISON'S "REPORT AND OBSERVATIONS ON THE MORTALITY OF THE GOVERNMENT LIFE ANNUITANTS." *

\section{To the Editor of the Assurance Magazine.}

Srr,-At this period, when the decennial census is on the point of being taken, it may not be out of place to call attention to the above Report, just issued, which happens to tonch upon certain points that have a peculiar interest at present, as bearing upon facts which may affect the correetness of any future life tables that may be computed upon the basis of the present census.

The Assurance Magazine is, therefore, an appropriate organ for directing the attention of actuaries, and through them of the public, to an interesting and most valuable document, which, being published in the shape of an unpalatable Blue-book, is not likely to come under general notice.

I propose to refer to such portions of the Report only as have a bearing on the census question, in relation to the false returns which the experience of previous censuses has shown to have been made with respect to the ages of females, to an extent probably hitherto little suspected, and to point out how the advance of science may be imperilled and retarded, and the pecuniary interests of the public sacrificed, as well by the false census returns as by the loose system which very generally obtains in the method adopted in practice of arriving at the ages of deceased persons, with the view to their being recorded in the books of the District Registrars.

With reference then to the first question, Mr. Finlaison, who from the nature of his appointment is peculiarly competent to form a correct opinion on such points, states that "it is the universal tendeney of persons supplying under no particular responsibility information of their own age or of that of their relations, to understate the truth when the party concerned is young, or not past middle age. On the other hand, where the person to be accounted for is old, there is a disposition to claim or attribute an exaggerated longevity." He explains that though errors in the reported ages of the dead may possibly to some extent counterbalance each other, this is never true of the reported ages of the living.

Mr. Finlaison quotes from the Report of the last census returns, vol. i., part ii., p. 24 , to show the extent of the results produced by individual mis-statements.

It is mentioned in that Report that "persons of the age of $20 \mathrm{in}$

* Report and Observations on the Mortality of the Government Liffe Annuitants. By Alexander Glen Finlaison, Actuary of the National Debt, 1860. Ordered by the House of Commons to be printed, 25 th Angust, 1860.

VOL. IX. 
1851 must have been 10 years of age in 1841, and persons of the age of 25 in 1851 must have been of the age of 15 in 1841; and as there is a certain number of losses by death, it is evident that, excluding the effects of migration, the numbers at age 20 to 25 in 1851 must be less than the numbers living at the age 10 to 15 in 1841, of whom they (20 to 25) are the natural survivors.

"What are the statements which the abstract of ages express?

" 1841 - The number of girls aged 10 to 15

was . . . . . . . $1,003,119$

1851-The number of young women aged

20 to 25 was, as stated in the returns - $1,030,456$

"Now, as the first number could never have swollen in 10 years to the magnitude of the second, we are driven to the hypothesis, that in 1841 and 1851 the heads of families returned several thousand ladies of the higher ages at the age of 20 to 25 ; and the hypothesis is confirmed by comparing the diminished numbers returned at the age 30 to 35 in 1851 with the numbers returned at 20 to 25 in 1841, where it is evident that the latter number is in deficiency as much as the former number is in excess.

" 1841 -The number of young women of the age 20 to 25 , as stated in the returns, was $.973,696$

1851 - The number of women of the age 30 to 35 , as stated in the returns, was . . 768,711"

The Report goes on to show that notwithstanding an acknowledged disturbing influence caused by the immigration of Irish into Great Britain during the 10 years 1841-51, " upon comparing the above numbers with those for males at the corresponding ages, the conclasion appears to be inevitable, that some 35,000 ladies, more or less, who have entered themselves in the second age, twenty to forty, really belong to the third age, forty to sixty. Thousands have allowed themselves to be called twenty, or some age near it, which happens to be the age at which marriage is commonly contracted in England."

If we could succeed in giving extensive publicity to such facts as these, and in bringing home to the minds of those who are weak enough, under the influence, no doubt, of some misplaced feeling of shame, to act in this foolish manner, and, if we could convince such people of the fact that statistical acumen is unerring in its power of detecting the falsities in such returns, we might succeed in checking the practice to which females are so prone of concealing, or of attempting to conceal, their true ages. And though it would be difficult, in individual cases, to prove the truth or falsehood of the statement as to a lady's age, let it be remembered that power of discovery in the gross undoubtedly exists, and that, by this power of 
detection, not only is discredit thrown upon the returns, but the whole female population is made the subject of ridicule, while a certain proportion only is to blame; and further-how unlikely it is, that any real concealment of age can ever take place among intimate friends; and as regards the census-enumerators, can they, by possibility, care one iota whether any particular lady of the thousands, the records of whose ages pass through their hands, is 'sweet eighteen,' or 'fair, fat, and forty'? Let such ladies read Horace, and learn that even flowers of spring do not for ever retain their pristine glory, and that the blushing moon does not always shine with unchanging aspect.

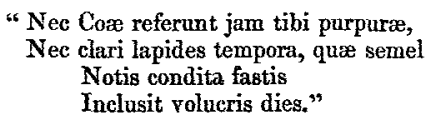

"Notis fastis," I may observe, may fairly be translated, "in the records of the Registrar-General."

We should, however, endeavour to make clear to the minds of the fair sex-who, in general, do not take much interest in statistical details - the exact nature and extent of the evils that are likely to result from the falsification of returns on which so many monetary schemes, in which they are more particularly interested, depend.

For whose benefit has the greater proportion of the enormous sum of two hundred millions sterling been assured upon lives in this country? Certainly for the benefit of the wives and daughters of England.

Of the 28,367 Government annuitants-which form the subject of Mr. Finlaison's Report, now under discussion-16,538 were females; and it is reasonable to suppose, that in the lives of the 11,829 males, which make up the first-mentioned number, several thousand more wives and daughters, and other female relations of the males, were pecuniarily interested.

Now, what must be the necessary result, as regards the use of recently constructed tables based upon what should be the proper elements for the ealculations of Life Assurance and Annuity Companies in this country-that is to say, upon the mortality and censuses of the country in which the transactions take place? Why, clearly this, that if, census after census, females persist in making false returns as to their ages, such Companies must secure themselves against the risk of any loss which may arise from the use of ineorrect data, and they must accordingly, in self-protection, take a sufficient margin for their own safety in offering terms for the different descriptions of benefits in which they deal.

The effect of this will be, that such increased premiums in the one case must be charged, and such reduced annuities granted in the other, in all cases where female lives are concerned, as shall compen- 
sate for all risk of errors in the returns which form the basis of the computations, upon the correctness of which the power of granting life assurances and annuities absolutely depends, and thus the public will fail to derive any advantage from improvements in statistical science, and the Companies will be compelled to continue the use of notoriously unscientifically constructed tables.

I may point out that, even if the result of the class of errors under observation should be actually in favour of the Companies in the gross, it would nevertheless be only just that, so long as such serions errors are found to exist, public Companies should protect themselves in the manner described against loss in granting either life assurances or annuities. As statistical returns come, in course of time, to be more correctly made, and accordingly more to be depended on, there can be no reason why females should be deprived of any possible advantage that they might derive from the use of tables which represent the mortality among their own sex.

If it should be clearly proved that the duration of life among females is actually greater than among males, a less premium for life assurance should be charged where the female sex is concerned; on the other hand, the charges for annuities depending on the lives of females should be higher than those for corresponding benefits on the lives of males.*

It is shown by the Government Life Tables that the mortality among males is higher than that among females throughout the whole of life.

Mr. Finlaison refers to a remarkable peculiarity shown by those tables-which were computed by the late Mr. Finlaison in 1823"a peculiarity at the age of 23 which is present in so many other observations, as to appear to be a law of nature. This feature consists in a marked increase of the mortality, at the particular age mentioned, which mortality afterwards diminishes to again re-augment to the same extent at an age long subsequent, viz., the age of 48 . The occurrence of a similar climax in the life of the mariner at the age of 32, has also been shown by separate observations drawn by different observers from independent sources. This peculiarity, however, does not exist in the female table of mortality. Nor is this remarkable variation," adds Mr. Finlaison, "altogether unimportant, for it militates against a theory supported by one or two eminent

* The only existing Company that quotes special rates for assurances on the lives of females is, I believe, the National Provident Institution. It appears from the prospectus of this Society that for assurances on the lives of females a small addition is made to the premiums charged for male lives, while the rates for annuities depending on the lives of females are less than those for similar benefits on the lives of males-as is the case with the Government Office and with many other Companies granting annuities. It would appear, therefore, that this Institution considers female vitality to be at once both inferior and superior to that of males - an apparent anomaly. The practice, however, of thus "working the oracle" might probably be defended. 
mathematicians, to the effect that mankind dies in the order of a symmetrical curve. Mankind, however, does not do so, as far as observation informs us."

Any opinion on this subject will naturally be interesting to your readers just now, considering the important discussion that has so recently taken place among the members of the Institute of Actuaries on Mr. Gompertz's law of mortality.

The result of the superiority of female over male life, as shown by the Government Life Table, is stated briefly as follows, viz.,- "In childhood-that is, at eight years of age-the female life is computed to possess $5 \frac{1}{2}$ years greater mean duration of life than the male; in womanhood-that is, at 28 years of age- $4 \frac{1}{2}$ years; at the age of 58 , $3 \frac{1}{2}$ years; and in old age-viz., 78 years of age $-1 \frac{1}{2}$ years." In drawing any inferences, however, from tables constructed upon the experience of Government as regards annuities and tontines, we must always bear in mind the well-known effect of the benefit of selfselection exercised by the nominees against the Government.

On this point Mr. Finlaison remarks-- "It may be doubted, indeed, whether any step in the way of selection will ever surpass the intuitive pereeption which reigns in the mind of the self-nominated annuitant at the time of purchase."

This influence, however, affects male no less than female lives.

Notwithstanding, then, the indications given by these tables, of the superiority of female over male life, and notwithstanding the fact that the mean future lifetime, or expectation of life, of females is greater than that of males, according to Dr. Farr's tables, still, considering the doubts that have been shown to exist as to the correctness of the data on which the latter tables were constructed, it will perhaps be admitted that the question of the superiority of female vitality is not yet set at rest, particularly, too, since the table founded on the experience of the seventeen Life Assurance Companies shows, that "the mortality amongst assured females, taking all ages together, is greater than amongst assured males."

It is probable, however, that even in the event of the vitality of females being positively proved to be superior to that of males, the female sex might not, on the whole, obtain any advantage from the use of tables of female mortality, since, no doubt, a considerably greater number of annuities than of assurances are granted upon the lives of females; but this is no reason why equitable charges should not be made in individual cases.

So long, however, as the records, on which the calculations of such descriptions of benefits depend, continue to be wilfully falsified by the return to the census-enumerators of incorrect ages, this will be impossible.

In connection with the question of the superiority of female over 
male life, Mr. Finlaison institutes a comparison between the English Life Table and the Government Life Annuitants' Table for both sexes. At the younger adult ages according to the English Life Table, the mortality among females is shown to be greater than that among males. "This conclusion," he says, "is eontrary to most previous experience. It is a result which is contrary also to nature. The sexes are not created in equal numbers. For every 20 females there are produced 21 males. But no fact is more thoroughly established than that, whenever the population is counted, the females are present in considerably greater number. Making every allowance for the temporary absence of a part of the male population, such a result conld not take place unless the stronger sex were subjected to a higher rate of mortality, and died off much faster than the females. Were it not so, and did not the males by their more rapid departure from the world subsequently compensate for their appearance in greater numbers in the first instance, it is evident that they would more and more preponderate at every successive enumeration."

I may mention that at corresponding ages the mortality of the female Government life annuitants appears, according to the table, to be considerably less than that of the males.

From what we have seen with respect to the census returns, there is probably great reason to doubt the correctness of the English Life Table as regards female lives; and though the same cannot be said of the male lives, still an Assurance Company would hardly adopt a table of mortality except in its entirety. If, therefore, this table came to be used at all, it would probably be a table based upon a combination of the two sexes-unless indeed the object should be to quote distinct rates for female life, and in this case the English Life Table could not probably with safety be made use of at present. It is to be regretted, however, that any circumstances should exist to prevent the use of tables founded upon the mortality of the country in which the grant of life assurances and annuities is carried on to so great an extent.

The English Life Table, construeted by Dr. Farr some years subsequent to the establishment of the Registrar-General's department for the registration of births, deaths, and marriages, naturally came to be considered peculiarly adapted for the use of Companies dealing in life contingencies-in the first place because the greater proportion of the business transacted by such Companies depended upon the lives of persons resident, for the most part throughout life, in the district embraced by the returns - and in the second place, because the table was based upon the records of the mortality experienced at a very reeent period, and upon the previous decennial census; the table in question, moreover, was due to a computer of the highest eminence.

Of course, as far as respects correctness of computation, the table may be fully relied on; but minuteness of calculation, and accuracy 
of records-supposing the returns of the Registrar-General can be depended upon-is of no avail, unless the census-enumerators succeed in obtaining exact information; for on the numbers living at each age, according to the periodical enumerations of the people, no less than upon the number of deaths, do our mortality tables depend.

I shall presently recur to the question of the accuracy of the mortuary records.

To show, practically, the effect in actual money of the use of the English Life Table in the grant of life annuities and assurances, Mr. Finlaison has computed that if 1,000 persons of each sex, all aged 55 years-the average age of entry at the Government Annuity Office-were to purchase life annuities, there would be found to be living, according to the English Life Table, at the expiration of 20 years, 368 males and 410 females-or, in all, 778 persons-for the future payment of whose annuities it would be neceseary to provide; but according to the experience of the Government Tables, at the expiration of the 20 years, the number surviving out of the 2,000 persons of both sexes would be as follows, viz., 403 males and 498 females-or, in all, 901 persons. There would therefore be, in fact, 123 persons to provide for in excess of the 778 for whom provision had been made. Assuming the annuities to have been $£ 60$ each-which Mr. Finlaison states to be the usual average-the Annuity Office would be liable to the extent of $£ 7,380$ per annum during the remainder of the lives of the surviving annuitants, for which no provision would have been made.

Again: supposing 1,000 males, all aged 27 years-which Mr. Finlaison considers to be a fair average age to assume*-were mutually to assure one another for the sum of $£ 1,000$ each, according to the mortality of the Government male annuitant lives, taking interest at 4 per cent., Mr. Finlaison computes that the annual premium payable, to assure the sum of $£ 1,000,000$, would be $£ 17,447$; while another 1,000 males, of the same age, would, according to the English Life Table for males, at the same rate of interest, have to provide the sum of $£ 16,885$ only annually, or $£ 562$ per annum less than the first set. At the expiration of 25 years there would be living, according to the Government Table, 712, and according to the English Life Table, 724, persons; and, in the case of the first society, Mr. Finlaison goes on to show that the sum of $£ 193,920$ would, according to its own table, buy up the 712 existing policies, while, in the case of the second society, the sum necessary to buy up the existing policies, according to the English Life Table, would amount to $£ 213,877$, to provide for which the second society would have been receiving annually, for 25 years,

* The experience of Life Offices would probably warrant the assumption of a much higher average age-possibly 40. 
the sum of $f 562$ a year less than the amount requisite to provide for the liability under the Annuitants' Mortality 'Table.

Upon reference to the first of these two illustrations, it will be seen that the differences between the numbers living at the age 75 , according to the English Life Table and Government Tables, were respectirely as follows, viz., males, 368 and 403 ; females, 410 and 498. The differences between these numbers are respectively 35 and 88. The variation between the tables was, therefore, considerably more than twice as great in the case of females as in that of males.

Now, without attributing the whole of the blame to false census returns-for, to do so, we must necessarily predicate the absence of all other errors and disturbing causes, as well as the absolnte correctness of the Government Life Annuitants' Table-there can be no doubt, from the foregoing considerations and illustrations, that the most mischievous results might readily be caused by use of the tables in question.

The latter illustration is less apposite to the purposes of this communication, since the mortality of male life only, according to the English Life Table, is made the subject of comparison with the Annuitants' Table; and it is to the effect of the errors in respect of the ages of females upon the safety of the table, that I desire particularly to confine my attention on the present occasion.

It is referred to, however, with the object of showing how important, in a monetary sense, is the choice of a proper table for any particular description of business.

As regards that illnstration, too, it may be mentioned that, in the ease of an Assurance Company, many elements must necessarily enter into the question of the choice of a mortality table that need not be considered by an Annuity Company, still less by the Government, whose object in granting life annuities is simply to exchange perpetual for terminable annuities, and not to make a profit of the transactions. A table, therefore, which might be perfectly suitable for the former, would be quite unfit for the latter, whatever be the direction in which the errors tend. I am now assuming what must probably always be the case in practice, viz., that all tables of mortality necessarily contain errors. A table that might be perfectly correct, would, I apprehend, be equally suitable for an Assurance or for an Annuity Company.

It would seem that if we could arrive at such an impossible result, and if we could moreover predict the rate of interest that would be realized during a long period of years, it would be sufficient for actuaries to make such additions to the net charges for the different risks undertaken as would be required to provide for the necessary profit on the several transactions, without, as they are now obliged to do, being compelled either to make an additional charge to compen- 
sate for errors in the data on which they base their computations, or to make use of tables which give a far too unfavourable view of life, and derive the required profit from the mortality falling short of that which the tables showed might be anticipated.

In the case of Assurance Companies, considering the unfortunate system of speculation in bonuses which now obtains to so great an extent, of course the further necessary addition would have to be made to provide for the bonuses which the cormorant-public now so eagerly demands. This abuse has crept into the system of assurance, owing, in a great measure, to the inaccuracy of the old mortality tables, and is one which, from what we have now seen of the possible flaws in Dr. Farr's model table, is not likely soon to be remedied.

Probably sufficient has been said to show how much it is in the interest of the entire community to assist in checking the tendency to falsify statistical records-for, in proportion as such returns become, in course of time, more correct, so will the public be more likely to obtain, on equitable terms, the benefits conferred by Life Assurance and Annuity Companies.

Another source of error, however, exists, which tends to jeopardise the value of mortality tables.

There is reason to believe that the returns of ages at death, made to the District-Registrars of Births, Deaths, aud Marriages, are in many cases far from correet.

It is a matter fully within the cognizance of those engaged in the business of life assurnnce, and who have constantly occasion to test the truth of these records, by means of proper documentary evidence of the dates of birth and baptism, that the ages of persons at death, as stated in the certificates of the Registrar, are often one, two, or more years greater or less than the correct age. Upon inquiring into the cause of such discrepancies, we discover how loose the system of arriving at the age at death really is. Upon a death occurring, it becomes the duty of the medical attendant of the deceased to fill up the certificate prescribed by the Act. This certificate, which must be signed by the gentleman who last attended the deceased, states the age last birthday-when last seen-the date and the cause of death. The time from the attack till death-each form of disease, or symptom, being reckoned from its commencement till death-is also required to be stated. Both the primary and secondary cause of death has also to be inserted. From this certificate, the entry is made in the books of the District-Registrar. Upon the truth, therefore, of the information furnished to the medical attendant, the correctness of the return entirely depends. Probably, in the majority of cases, the medical man has no intimate acquaintance with his patient, and in very many cases he is called in towards the close of life, and after the patient has been ill for some time. His power, therefore, of forming a satisfactory 
independent judgment as to the probable correctness of the age, as stated to him by the relatives, is very much diminished, owing to the change in the appearance of the patient which disease has caused. The medical attendant must therefore, in most cases, be wholly at the mercy of his informants, who have often but a very imperfect knowledge themselves of the fact they are required to certify, and in a great number of cases, therefore, the age is assessed altogether at hazard.

The ideas of medical men differ very much as to the importance of statistical returns. One class will set down, without exercising any judgment in the matter, any age that may be given to them. Another will endeavour to arrive at the truth, should it seem likely that the deceased were older or younger than the age asserted. Now both these classes aid in assisting the registration of incorrect agesthe first by taking no trouble in the matter, and the second by selfdeception as to the age of a person they have perhaps only seen upon a bed of sickness.

We all know how difficult it is to judge correctly even of the ages of persons in health, whom we are in the habit of seeing every day, in consequence of the varying effect produced upon the constitution by the wear and tear of life in the ever-changing circumstances in which different people are placed. Although, therefore, medical men of experience are, no doubt, better qualified than non-professional men to form a correct estimate of the age of persons at death, and to make the necessary allowances for the effect produced by the antecedent illness, I think it will be admitted that according to the system now in operation for recording the age at death, the returns are liable to be often very far from the truth.

The simple remedy for this evil would be to require that the medical attendant should give information as to facts only of which he is actually cognizant-that is to say, of the date and cause of death and duration of the illness, leaving it for the legal representative or next of kin of the deceased to furnish the Registrar with the age at death, the statement of which should be supported by documentary evidence to be furnished within a certain time after the date of death.

It would clearly be inconvenient to require that this evidence should be procured within a few days of the event; and the execution of the medical certificate could not be deferred, because the clergy are very properly not allowed to proceed to the interment of a body without the production of the Registrar's certificate, which, as previously mentioned, is based upon that of the medical attendant.

In connection with this subject, and referring to the remark of Mr. Finlaison, that "where the person to be accounted for is old, there is a disposition to claim or attribute an exaggerated longevity," I may observe that in very many of those cases where the frequent remarkable statements as to the ages which persons are registered as having 
attained come to be subjected to the test of actual documentary evidence, it has been found that such ages are for the most part ridiculously overstated.

It is a curious fact, and one which should influence us in denying credence to extravagant statements of this kind, unless supported by satisfactory evidence, that it is not found that members of the Pecrage, whose ages at death we have instant means at hand for aseertaining, ever attain to fabulous old age. If, therefore, this favoured class do not present cases of extreme longevity, it is reasonable that we should receive with great caution such statements as to the ages of members of other classes of the community.

Probably, with very rare exceptions, the maximum age obtained in this country never really much exceeds 100 years.

The object. I have had in view in this. letter, has been to direct attention to certain facts, with the view to the remedy of any possible flaws that may be admitted to exist in the system of the censusenumeration and the registration of deaths in this conntry, as affecting the accuracy of any future tables of mortality which may be computed upon such data-tables on which all calculations connected with life contingencies depend.

The principal heads are as follow, viz.:-

1. The inordinate extent to which the ages of females between the ages of-say, 20 and 40 -are understated in the census.

2. The over-estimate of age in very advanced life, both in the census and in the registers of death.

3. The loose system adopted in ascertaining the ages at death of all classes of people, at all ages.

4. The direct pecuniary loss sustained by females in the purehase from the Grovernment, or from such Annuity Companies as adopt special scales for female lives, on the present assumption of the vitality of females being so much in excess of that of males.

5. The advantage the female sex might derive, were Life Assurance Companies to adopt special rates of premium for female lives.

6. The general discredit thrown upon the English Life Table, both for males and females, and the necessity that exists for Life $\Lambda$ ssurance and Annuity Companies to abstain from using it, in consequence of the incorrect returns, which both as regards the numbers living and the numbers dying, at each agc, have becn, no doubt, habitually made to the census-enumerators and to the District Registrars of Deaths.

'I'he limits of a letter like the present will not allow of my cven touching upon many other points which might affect the question of the suitability or otherwise, for the purposes of Life Assurance and $\Lambda$ nnuity Companies, of any life tables based upon the consus returns; one of which is the fact that the labouring elasses, as well as paupers, vagrants, criminals, and dissolute persons, comprise, by far, the larger 
proportion of the whole population; and it is not upon such lives that assurances and annuities are granted.

The mortality, too, among these classes is undoubtedly greater than that among those who rank higher in the social scalc-as I have recently had an opportunity of showing, in a paper published in the Transactions of the Institute of Actuaries, in the course of which this question was entered into at considerable length. On the other hand, it might be urged that a table containing so large a number of lives cxposed to an undue rate of mortality would be, for that very rcason, more suited to the requirements of public Companies.

A discussion, however, even of this one question, would lead to an inquiry into the respectire merits and demcrits of the existing tables of mortality, and would cause me to engross far too much of the available space in the pages of the Assurance Magazine. The effect, too, of the exclusion from the census returns - notwithstanding all the care to prevent it-of a considerable proportion of the nomadic population of the country, as well as of numerous other influenees, would have to be considered.

In conclusion, I may state that Mr. Finlaison-who, in connection with his recent Report, has evidently investigated and considered this subject most fully-is clearly of opinion, that "at the present day, the census, and registration of births, deaths, and marriages, cannot with prudence be adopted as the bases of the true measure of the value of life."

$$
\text { I am, Sir, }
$$

Your obedient servant,

Allianee Assuranee Company, H. W. PORTER.

$16 t h$ March, 1861.

ON MR. GOMPERTZS LAW OF HUMAN MORTALITY, AND MR. EDMONDS'S CLAIMS TO ITS INDFPWNDHNT DISCOVERY $\Lambda$ ND IXTENSION.

\section{To the Editor of the Assurance Mayazine.}

Sin,-The remarks which appeared from the pen of Professor De Morgan in the number of the Assurance Magazine for last Jnly, must have attracted the notice, not only of those who are interested in the history of the theory of life contingencies, but of all your readers who wish to see improvements in science attributed to their actual originators. It is no unasual thing for the title to a discovery to be contested; and it not uncommonly appears that different persons bave made the same discovery independently. This is sometimes an extremely difficult point to decide; but in the present casc, the means of arriving at a satisfactory decision are unusnally ample. It must be clear to all who have read Professor De Morgan's remarks and Mr. Edmonds's rejoinder, that the eharge bronght by the former against the latter has been completely substantiated: viz., that Mr. Edmonds, following in the footsteps of Mr. Gompertz, and familiar with his writings, "has adopted his ideas without anything 